\title{
PENINGKATAN MINAT BELI KONSUMEN MELALUI DAYA TARIK IKLAN DAN LABEL HALAL PRODUK LIPCREAM EMINA PADA UNIVERSITAS MUHAMMADIYAH TANGERANG
}

\author{
Ismayudin Yuliyzar ${ }^{1}$ \\ Fakultas Ekonomi dan Bisnis, Universitas Muhammadiyah Tangerang \\ Ismayudin_yulizar@yahoo.co.id \\ Shely Devi Enjelita ${ }^{2}$ \\ Fakultas Ekonomi dan Bisnis, Universitas Muhammadiyah Tangerang
}

\begin{abstract}
ABSTRAK
Wanita tentu ingin selalu tampil cantik dimana pun kapan pun. Banyak yang dilakukan untuk mendapatkan tampilan yang diinginkan agar terlihat menawan. Hal yang paling umum dilakukan bagi kaum wanita adalah memakai produk-produk kosmetik. Tak banyak juga sebagian masyarakat yang masih kurang memperhatikan keamanan dan kehalalan suatu produk. Penelitian ini bertujuan untuk menganalisis pengaruh Daya Tarik Iklan dan Label Halal terhadap Minat Beli Konsumen di Universitas Muhammadiyah Tangerang. Sampel penelitian ini adalah 80 responden pelanggan di Universitas Muhammadiyah Tangerang dari populasi 425 pelanggan. Metode yang digunakan adalah metode kuantitaif. Pengumpulan data primer diperoleh dari penyebaran kuesioner.Hasil penelitian menunjukkan bahwa secara parsial variabel Daya Tarik Iklan (X1) berpengaruh secara positif terhadap Minat Beli Konsumen (Y) dan Label Halal (X2) berpengaruh secara positif terhadap Minat Beli Konsumen (Y). Dan secara simultan variabel Daya Tarik Iklan (X1) dan Label Halal (X2) berpengaruh secara positif terhadap Minat Beli Konsumen (Y).

Kata kunci :Daya Tarik Iklan, Label Halal, Minat Beli Konsumen
\end{abstract}

\begin{abstract}
Women certainly want to always look beautiful wherever and whenever. A lot is being done to get the look you want to look good. The most common thing done for women is to use cosmetic products. Not too many people are still not paying attention to the safety and halalness of a product. This study aims to analyze the influence of the Attractiveness of Advertising and Halal Labels on Consumer Purchase Interest at the University of Muhammadiyah Tangerang. The sample of this study was 80 customer respondents at the University of Muhammadiyah Tangerang from a population of 425 customers. The method used is a quantitative method. Primary data collection was obtained from distributing questionnaires. The results showed that partially the Attractiveness of Advertising variable (X1) had a positive effect on Consumer Purchase Interest (Y) and the Halal Label (X2) has a positive effect on Consumer Purchase Interest ( $Y$ ). And simultaneously the Attractiveness of Advertising variable (X1) and Halal Label (X2) has a positive effect on Consumer Purchase Interest $(Y)$.
\end{abstract}

Keywords: Attractiveness of Ads, Halal Labels, Consumer Buying Interest 


\section{A. PENDAHULUAN}

Wanita tentu ingin selalu tampil cantik dimana pun kapan pun. Banyak yang dilakukan untuk mendapatkan tampilan yang diinginkan agar terlihat menawan. Hal yang paling umum dilakukan bagi kaum wanita adalah memakai produk-produk kosmetik. Kosmetik sudah menjadi suatu kebutuhan untuk sebagian wanita, terlebih untuk tampil menarik dengan menggunakan berbagai varian kosmetik. Agar tampil lebih cantik dan menarik. Konsumen harus selektif dalam memilih merek kosmetik yang sesuai dengan kebutuhannya. Kesadaran masyarakat tentang keamanan kosmetik yang digunakannya sudah semakin meningkat sejalan dengan munculnya berbagai kasus dampak penggunaan bahan berbahaya dalam kosmetika secara terbuka.

Tak banyak juga sebagian dari masyarakat yang masih kurang memperhatikan tentang keamanan kosmetik yang digunakannya. Selain itu, kehalalan suatu produk kosmetik juga menjadi pertimbangan para konsumen, terutama konsumen muslim. Produk kosmetik memang tidak dimakan dan masuk ke dalam tubuh. Oleh karena itu kosmetik biasanya dikaitkan dengan masalah suci atau najis. Produk tersebut bisa dikatakan haram jika produk kosmetik tersebut mengandung bahan-bahan najis, yang tidak baik untuk manusia. Istilah halal dalam kehidupan sehari-hari sering digunakan untuk makanan ataupun minuman yang diperolehkan untuk dikonsumsi menurut syariat islam. Sedangkan dalam konteks luas istilah halal merujuk kepada segala sesuatu baik itu tingkah laku, aktifitas, maupun cara berpakaian dan lain sebagainya yang diperbolehkan atau diizinkan oleh hukum Islam.

Label halal merupakan pencantum tulisan atau pernyataan halal pada kemasan produk untuk menunjukan bahwa produk yang dimaksud berstatus sebagai produk halal. Kehalalan akan menjadi penting dalam kajian pemasaran di Indonesia, karena saat ini konsumen akan memperlihatkan label halal yang tertera pada produk yang di perjual belikan pada pasar. Masih banyak juga kosmetik yang beredar tanpa adanya label halal dalam kemasan produknya dan tidak pasti akan kehalalannya serta keamanannya, akan tetapi masih banyak masyarakat yang mengkonsumsinya. Pada era globalisasi ini khususnya hampir semua wanita memakai kosmetik dan yang paling sering digunakan atau dibeli yaitu lipcream, karna sebagian wanita berfikir dengan memakai lipstick atau lipcream dapat mengubah suatu penampilan.

Walaupun kosmetik halal bukan sesuatu yang dimakan atau masuk ke dalam tubuh, kita tetap harus cermat memperhatikan jangan sampai kita menggunakan produk kosmetik yang berbahan najis karena ketentuan hukum islam sendiri sudah jelas bahwa ada aspek halal, haram dan najis. Umat muslim percaya bahwa dengan mengkonsumsi makanan yang halal akan menjadi berkah dan sehat untuk manusia. Karena pengetahuan sebagian masyarakat akan kata halal demi 
kebaikan dan kesehatan maka di era globalisasi ini sebagian dari masyarakat mulai mencari produkproduk yang tercantum label halal karena islam mengajarkan kita agar senantiasa untuk mengkonsumsi yang ada dimuka bumi yang serba halal dan baik, baik makanan dan minuman bahkan selain itu seperti kosmetik, obat-obatan dan lainlainnya.

Kosmetik dan obat-obatan keduanya disebut halal apabila bahan-bahan yang terkandung dalam keduanya harus dari bahan baku pilihan yang sesuai syariat islam dan memiliki sertifikat halal dari Majelis Ulama Indonesia. Minat beli dipengaruhi oleh dua faktor yakni faktor internal dan faktor eksternal. Internal diri konsumen, yang berupa motivasi, persepsi, perasaan dan emosinya merupakan faktor internal. Sedangkan, hal-hal usaha pemasaran dan faktor sosial budaya merupakan faktor eksternal. Minat beli adalah sesuatu yang diperoleh dari proses belajar dan proses pemikiran yang membentuk suatu persepsi. Minat beli ini menciptakan suatu motivasi yang terus terekam dalam benaknya dan menjadi suatu keinginan yang sangat kuat yang pada akhirnya ketika seorang konsumen harus memenuhi kebutuhannya akan mengaktualisasikan apa yang ada dibenaknya itu.

Menonton iklan merupakan bentuk strategi dalam memberikan atau memperkenalkan informasi mengenai produk yang dipamerkan. Serta dapat diketahui bahwa intensitas menonton tayangan iklan cukup mampu mendorong konsumen dalam pembelian produk. Dorongan konsumen dalam pembelian produk diperoleh dari aspek psikologi. Dimana aspek psikologi ini bertujuan untuk memunculkan timbulnya dorongan minat dalam diri konsumen setelah melihat iklan yang ditayangkan. Daya tarik dalam iklan menjadi hal yang sangat penting agar iklan mampu berkomunikasi dengan konsumen, dapat membujuk dan membangkitkan serta mempertahankan ingatan konsumen akan produk yang ditawarkan.

\section{B. KAJIAN LITERATUR DAN PENGEMBANGAN HIPOTESIS}

\section{Pengertian Iklan}

Menurut Donni Juni (2017:174) mengatakan bahwa: iklan adalah sebagai segala bentuk pesan tentang produk perusahaan/pemasar yang disampaikan oleh perusahaan/pemasar melalui berbagai media dan dibiayai oleh perusahaan/pemasar, yang ditujukan bagi kalangan tertentu atau masyarakat secara luas. Periklanan adalah keseluruhan proses yang meliputi penyiapan, perencanaan, pelaksanaan, dan pengawasan dalam penyampaian iklan.

\section{Pengertian Label Halal}

Menurut Yuswohady (2014:61) mengatakan bahwa: salah satu label yang tercantum pada produk adalah label halal. Label halal adalah jaminan yang diberikan oleh suatu lembaga yang berwenang seperti Lembaga Pengkajian Pangan Obat-Obatan 
dan Kosmetika Majelis Ulama Indonesia (LP POM MUI) untuk memastikan bahwa produk tersebut sudah lolos pengujian kehalalan sesuai syariat Islam. Pencantuman label halal bertujuan agar konsumen mendapatkan perlindungan kehalalan dan kenyamanan atas pemakaian produk tersebut.

\section{Pengertian Minat Beli Konsumen}

Menurut Ali Hasan (2014:173) mengatakan bahwa: minat beli merupakan sesuatu yang berhubungan dengan rencana konsumen untuk membeli produk tertentu. Dapat dikatakan bahwa minat beli merupakan pernyataan mental dari konsumen yang merefleksikan rencana pembelian sejumlah produk dengan merek tertentu. Hal ini sangat diperlukan oleh para pemasar untuk mengetahui minat beli konsumen terhadap suatu produk, baik para pemasar maupun ahli ekonomi menggunakan variabel minat untuk memprediksi perilaku konsumen dimasa yang akan datang. Minat beli masa mendatang sangat dipengaruhi oleh pelanggan-pelanggan yang berkaitan dengan harga, merek, promosi, iklan, rantai pasokan, kombinasi (mix) layanan, suasana, dan lokasi (tempat).

\section{Hipotesis Penelitian}

Menurut

Sugiyono

(2017:159) menyatakan hipotesis merupakan jawaban sementara terhadap rumusan masalah penelitian, dimana rumusan masalah penelitian telah dinyatakan dalam bentuk kalimat pernyataan. Dinyatakan sementara, karena jawaban yang diberikan baru didasarkan pada fakta-fakta empiris yang diperoleh melalui pengumpulan data. Jadi, hipotesis juga dapat dinyatakan sebagai jawaban teoritis terhadap rumusan masalah penelitian, belum jawaban yang empirik dengan data.

Dari uraian masalah yang ada dapat dimunculkan syarat hipotesis penelitian ini sebagai berikut:

H1: Diduga Daya Tarik Iklan mempunyai pengaruh terhadap Minat Beli Konsumen pada pembelian Lipcream Emina

H2: Diduga Label Halalmempunyai pengaruh terhadap Minat Beli Konsumen pada pembelian Lipcream Emina

H3: Diduga Daya Tarik Iklan, Label Halal mempunyai pengaruh terhadap Minat Beli Konsumen pada pembelian Lipcream Emina

\section{METODE PENELITIAN}

\section{Jenis Penelitian}

Metode penelitian yang penulis gunakan dalam penelitian ini adalah penelitian Deskriptif Asosiatif, untuk mengetahui pengaruh hubungan antara dua variabel atau lebih. Peneliti melakukan perlakuan dalam pengumpulan data, misalnya dengan mengedarkan kuesioner, 
wawancara terstruktur, dan sebagainya.

\section{Penentuan Populasi dan Sampel} populasi adalah wilayah generalisasi yang terdiri atas : obyek atau subyek yang memunyai kualitas dan karakteristik tertentu yang ditetapkan oleh peneliti untuk dipelajari dan kemudian ditarik kesimpulannya.

(Sugiyono 2018:80). Populasi dalam penelitian ini adalah 80 mahasiswi Universitas Muhammadiyah Tangerang.

Sampel merupakan bagian dari jumlah dan karakteristik yang dimiliki oleh populasi tersebut (Sugiyono 2018:81). Bila populasi besar, dan peneliti tidak mungkin mempelajari semua yang ada pada populasi, maka peneliti dapat menggunakan sampel yang diambil dari populasi itu. Samping yang digunakan dalam penelitian ini menggunakan sampling jenuh, dimana semua anggota populasi dijadikan sampel.

\section{Jenis dan Sumber Data}

Untuk memperoleh data yang sesuai dengan permasalahan penelitian, maka digunakan metode pengumpulan sumber data primer dan skunder (Sugiyono,2018)

\section{Metode Pengumpulan Data}

Menggunakan metode pengumpulan data yang digunakan dalam penelitian adalah Kuesioner.

\section{Metode Analisis Data}

\section{a. Uji Validitas}

Menunjukan derajat ketetapan antara data yang sesungguhnya terjadi pada objek dengan data yang dikumpulkan oleh peneliti Sugiyono (2017:267)

\section{b. Uji Reabilitas}

Berkenaan dengan derajat konsistensi dan stabilitas data atau temuan. Dalam penelitian kuantitatif suatu data dinyatakan reliabel apabila dua atau lebih peneliti dalam obyek yang sama, atau peneliti sama dalam waktu berbeda menghasilkan dua yang sama, atau sekelompok data bila dipecah menjadi dua menunjukan data yang tidak berbeda Sugiyono (2017:268)

\section{Analisis Regresi Linier Sederhana \\ Analisis regresi linear sederhana adalah sebuah} pendekatan yang digunakan untuk mendifinasikan hubungan linier antara satu variabel predictor (independen, $\mathrm{X}$ ) dan satu variabel respon (dependen, Y) Sugiyono (2017:188)

\section{Analisis Regresi Linier Berganda}

Analisis regresi linear berganda merupakan teknik analisis yang digunakan untuk melihat pengaruh dari beberapa prediktor terhadap kriterium Sugiyono (2017:192)

\section{Analisis Korelasi Sederhana}

Kegunaan analisis korelasi sederhana untuk mengetahui 
derajat hubungan antara variabel bebas $\mathrm{X}$ (Independen) dengan variabel terikat Y (Dependen)

\section{Analisis Korelasi Berganda}

Digunakan untuk mencari hubungan antara dua variabel bebas atau lebih yang secara bersama-sama dihubungkan dengan variabel terikat.

\section{Pengujian Hipotesis}

a. Analisis

Koefisien

Determinasi

Uji koefisien determinasi

$\left(\mathrm{R}^{2}\right)$ digunakan untuk mengukur seberapa jauh kemampuan model dalam menerangkan minat beli konsumen. Nilai koefisien determinasi adalah antara nol sampai satu. Nilai $R^{2}$ yang kecil berarti kemampuan Daya Tarik Iklan dan Label Halal dalam menjelaskan minat beli konsumen sangat terbatas. Sedangkan nilai yang mendekati satu berarti Daya Tarik Iklan dan Label Halal memberikan hampir semua informasi yang dibutuhkan untuk memprediksi minat beli konsumen.

\section{b. Uji t (Secara Persial)}

Uji t digunakan untuk mengetahui apakah masingmasing variabel bebasnya secara sendiri-sendiri berpengaruh secara signifikan terhadap variabel terikatnya.

\section{c. Uji F}

Uji $F$ adalah pengujian signifikasi yang digunakan untuk mengetahui seberapa besar pengaruh variabel bebas (X1 dan X2) secara bersamasama terhadap variabel terikat (Y).

\section{HASIL PENELITIAN DAN PEMBAHASAN}

Berdasarkan hasil penelitian yang telah dilakukan terhadap 80 responden melalui penyebaran kuesioner. Untuk mendapatkan kecenderungan jawaban responden terhadap jawaban masing-masing variabel akan didasarkan pada rentang skor jawaban sebagaimana pada lampiran. 


\section{Analisis Statistik Deskriptif}

a. Deskriptif Variabel Daya Tarik Iklan

Variabel daya tarik iklan pada penelitian ini diukur melalui 10 pertanyaan yang mempresentasikan indikator-indikator dari variabel tersebut. Hasil tanggapan terhadap daya tarik iklan.

Tabel 4.1

Tanggapan Responden Terhadap Daya Tarik Iklan

\begin{tabular}{|c|c|c|c|c|c|}
\hline Pernyataan & STS (1) & TS (2) & RR (3) & S (4) & SS (5) \\
\hline X1.1 & 0 & 0 & 1 & 3 & 76 \\
\hline X1.2 & 0 & 2 & 20 & 21 & 37 \\
\hline X1.3 & 0 & 1 & 10 & 41 & 28 \\
\hline X1.4 & 0 & 1 & 16 & 36 & 27 \\
\hline X1.5 & 1 & 0 & 9 & 38 & 32 \\
\hline X1.6 & 0 & 1 & 12 & 35 & 32 \\
\hline X1.7 & 0 & 2 & 11 & 40 & 27 \\
\hline X1.8 & 0 & 1 & 11 & 32 & 36 \\
\hline X1.9 & 0 & 0 & 13 & 27 & 40 \\
\hline X1.10 & 0 & 2 & 20 & 21 & 37 \\
\hline
\end{tabular}

\section{b. Deskriptif Variabel Label Halal}

Variabel label halal pada penelitian ini diukur melalui 10 pertanyaan yang mempresentasikan indikator-indikator dari variabel tersebut. Hasil tanggapan terhadap label halal.

Tabel 4.2

Tanggapan Responden Terhadap Label Halal

\begin{tabular}{|c|c|c|c|c|c|}
\hline Pernyataan & STS (1) & TS (2) & RR (3) & S (4) & SS (5) \\
\hline X1.1 & 0 & 0 & 6 & 36 & 38 \\
\hline X1.2 & 0 & 0 & 15 & 38 & 27 \\
\hline X1.3 & 0 & 2 & 13 & 41 & 24 \\
\hline X1.4 & 0 & 0 & 9 & 40 & 31 \\
\hline X1.5 & 0 & 1 & 13 & 41 & 25 \\
\hline X1.6 & 0 & 4 & 8 & 36 & 32 \\
\hline X1.7 & 0 & 1 & 13 & 37 & 29 \\
\hline X1.8 & 0 & 0 & 13 & 35 & 32 \\
\hline X1.9 & 0 & 1 & 13 & 41 & 25 \\
\hline X1.10 & 0 & 0 & 15 & 38 & 27 \\
\hline
\end{tabular}




\section{c. Deskriptif Variabel Minat Beli Konsumen}

Variabel minat beli konsumen pada penelitian ini diukur melalui 10 pertanyaan yang mempresentasikan indikator-indikator dari variabel tersebut. Hasil tanggapan terhadap minat beli konsumen.

Tabel 4.3

Tanggapan Responden Terhadap Minat Beli Konsumen

\begin{tabular}{|c|c|c|c|c|c|}
\hline Pernyataan & STS (1) & TS (2) & RR (3) & S (4) & SS (5) \\
\hline X1.1 & 40 & 0 & 13 & 0 & 0 \\
\hline X1.2 & 18 & 2 & 20 & 2 & 0 \\
\hline X1.3 & 27 & 1 & 8 & 1 & 0 \\
\hline X1.4 & 37 & 2 & 7 & 2 & 0 \\
\hline X1.5 & 24 & 2 & 14 & 2 & 0 \\
\hline X1.6 & 25 & 0 & 12 & 0 & 0 \\
\hline X1.7 & 24 & 2 & 13 & 2 & 0 \\
\hline X1.8 & 32 & 0 & 9 & 0 & 1 \\
\hline X1.9 & 40 & 0 & 13 & 0 & 0 \\
\hline X1.10 & 32 & 4 & 8 & 4 & 0 \\
\hline
\end{tabular}

\section{Analisis Data}

\section{a. Uji Kualitas Data}

\section{1) Pengujian Validitas}

Uji validitas dilakukan untuk mengetahui kelayakan setiap butir-butir dalam suatu daftar pernyataan. Uji ini dilakukan untuk mengukur data yang telah didapat setelah penelitian. Uji validitas akan menguji masing-masing variabel yang digunakan dalam penelitian ini.

Tabel 4.4

Hasil Uji Validitas Variabel Daya Tarik Iklan (X1)

\begin{tabular}{|c|c|c|c|c|}
\hline Variabel & $\begin{array}{c}\text { Item } \\
\text { Pernyataan }\end{array}$ & $\begin{array}{c}\mathrm{r} \\
\text { hitung }\end{array}$ & $\mathrm{r}$ table & Keterangan \\
\hline \multirow{10}{*}{$\begin{array}{l}\text { Daya Tarik } \\
\text { Iklan (X1) }\end{array}$} & Pernyataan 1 & 0,740 & 0,185 & Valid \\
\hline & Pernyataan 2 & 0,656 & 0,185 & Valid \\
\hline & Pernyataan 3 & 0,696 & 0,185 & Valid \\
\hline & Pernyataan 4 & 0,599 & 0,185 & Valid \\
\hline & Pernyataan 5 & 0,657 & 0,185 & Valid \\
\hline & Pernyataan 6 & 0,764 & 0,185 & Valid \\
\hline & Pernyataan 7 & 0,699 & 0,185 & Valid \\
\hline & Pernyataan 8 & 0,645 & 0,185 & Valid \\
\hline & Pernyataan 9 & 0,740 & 0,185 & Valid \\
\hline & Pernyataan 10 & 0,563 & 0,185 & Valid \\
\hline
\end{tabular}


Tabel 4.5

Hasil Uji Validitas Variabel Label Halal (X2)

\begin{tabular}{|c|l|c|c|c|}
\hline \multirow{4}{*}{ Variabel } & $\begin{array}{c}\text { Item } \\
\text { Pernyataan }\end{array}$ & $\begin{array}{c}\mathrm{r} \\
\text { hitung }\end{array}$ & r table & Keterangan \\
\hline \multirow{5}{*}{$\begin{array}{c}\text { Label Halal } \\
\text { (X2) }\end{array}$} & Pernyataan 1 & 0,590 & 0,185 & Valid \\
\cline { 2 - 5 } & Pernyataan 2 & 0,762 & 0,185 & Valid \\
\cline { 2 - 5 } & Pernyataan 3 & 0,744 & 0,185 & Valid \\
\cline { 2 - 5 } & Pernyataan 4 & 0,738 & 0,185 & Valid \\
\cline { 2 - 5 } & Pernyataan 5 & 0,720 & 0,185 & Valid \\
\cline { 2 - 5 } & Pernyataan 6 & 0,593 & 0,185 & Valid \\
\cline { 2 - 5 } & Pernyataan 7 & 0,667 & 0,185 & Valid \\
\cline { 2 - 5 } & Pernyataan 8 & 0,608 & 0,185 & Valid \\
\cline { 2 - 5 } & Pernyataan 9 & 0,735 & 0,185 & Valid \\
\cline { 2 - 5 } & Pernyataan 10 & 0,762 & 0,185 & Valid \\
\hline
\end{tabular}

Tabel 4.6

Hasil Uji Validitas Variabel Minat Beli Konsumen (Y)

\begin{tabular}{|c|l|c|c|c|}
\hline \multirow{4}{*}{ Variabel } & \multicolumn{1}{|c|}{$\begin{array}{c}\text { Item } \\
\text { Pernyataan }\end{array}$} & $\begin{array}{c}\mathrm{r} \\
\text { hitung }\end{array}$ & r table & Keterangan \\
\hline \multirow{4}{*}{$\begin{array}{c}\text { Minat Beli } \\
\text { Konsumen } \\
\text { (X2) }\end{array}$} & Pernyataan 1 & 0,685 & 0,185 & Valid \\
\cline { 2 - 5 } & Pernyataan 2 & 0,664 & 0,185 & Valid \\
\cline { 2 - 5 } & Pernyataan 3 & 0,690 & 0,185 & Valid \\
\cline { 2 - 5 } & Pernyataan 4 & 0,632 & 0,185 & Valid \\
\cline { 2 - 5 } & Pernyataan 5 & 0,678 & 0,185 & Valid \\
\cline { 2 - 5 } & Pernyataan 6 & 0,742 & 0,185 & Valid \\
\cline { 2 - 5 } & Pernyataan 7 & 0,702 & 0,185 & Valid \\
\cline { 2 - 5 } & Pernyataan 8 & 0,645 & 0,185 & Valid \\
\cline { 2 - 5 } & Pernyataan 9 & 0,671 & 0,185 & Valid \\
\cline { 2 - 5 } & Pernyataan 10 & 0,583 & 0,185 & Valid \\
\hline
\end{tabular}

\section{2) Pengujian Reabilitas}

Uji reabilitas digunakan untuk mengukur suatu kuesioner yang merupakan indikator dari suatu variabel. Reabilitas diukur dengan uji statistic Cronbach's Alpha $(0,60)$. 
Tabel 4.7

Hasil Uji Reabilitas

\begin{tabular}{|c|c|c|c|}
\hline Variabel & $\begin{array}{c}\text { Cronbach's } \\
\text { Alpha }\end{array}$ & $\begin{array}{c}\text { Standar } \\
\text { Reabilitas }\end{array}$ & Status \\
\hline Daya Tarik Iklan & 0,865 & 0,60 & Reliabel \\
\hline Label Halal & 0,878 & 0,60 & Reliabel \\
\hline Minat Beli Konsumen & 0,878 & 0,60 & Reliabel \\
\hline
\end{tabular}

Dari hasil reabilitas bahwa masing-masing dari setiap variabel yaitu, daya tarik iklan, label halal dan minat beli konsumen dinyatakan reliabel karena memiliki nilai Cronbach's Alpha lebih besar dari 0,60.

\section{b. Analisis Regresi}

\section{1) Analisis Regresi Linier Sederhana}

Tabel 4.8

Analisis Regresi Sederhana Variabel Daya Tarik

Iklan Terhadap Minat Beli Konsumen

\begin{tabular}{|c|c|c|c|c|c|c|}
\hline \multicolumn{7}{|c|}{ Coefficients $^{a}$} \\
\hline \multirow{2}{*}{\multicolumn{2}{|c|}{ Model }} & \multicolumn{2}{|c|}{$\begin{array}{l}\text { Unstandardized } \\
\text { Coefficients }\end{array}$} & \multirow{2}{*}{$\begin{array}{c}\begin{array}{c}\text { Standardize } \\
d \\
\text { Coefficients }\end{array} \\
\text { Beta }\end{array}$} & \multirow[t]{2}{*}{$t$} & \multirow[t]{2}{*}{ Sig. } \\
\hline & & B & $\begin{array}{l}\text { Std. } \\
\text { Error }\end{array}$ & & & \\
\hline \multirow[t]{2}{*}{1} & (Constant) & 9,773 & 2,600 & & 3,759 &, 000 \\
\hline & $\begin{array}{l}\text { Daya Tarik } \\
\text { Iklan }\end{array}$ & ,750 & ,060 & ,816 & $\begin{array}{r}12,45 \\
8\end{array}$ &, 000 \\
\hline
\end{tabular}

Berdasarkan tabel diatas dapat diketahui regresi linier daya tarik iklan terhadap minat beli konsumen dengan nilai konstanta sebesar 9,773, artinya jika daya tarik iklan nilainya 0 , maka tingkat minat beli konsumen sebesar 9,773.

Tabel 4.9

Analisis Regresi Sederhana variabel

LabelHalal Terhadap Minat Beli Konsumen

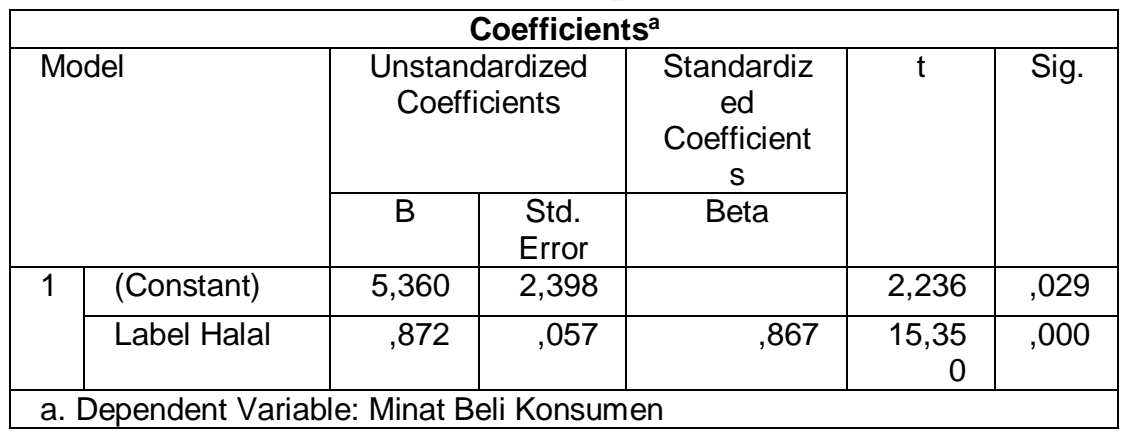


Berdasarkan tabel diatas dapat diketahui regresi linier label halal terhadap minat beli konsumen dengan nilai konstanta sebesar 5,360, artinya jika label halal nilainya 0 , maka tingkat minat beli konsumen sebesar 5,360.

\section{2) Analisis Regresi Linier Berganda}

Tabel 4.10

Analisis Regresi Berganda Variabel Daya Tarik Iklan

Dan Label Halal Terhadap Minat Beli Konsumen

\begin{tabular}{|c|c|c|c|c|c|c|}
\hline \multicolumn{7}{|c|}{ Coefficients $^{a}$} \\
\hline \multirow{2}{*}{\multicolumn{2}{|c|}{ Model }} & \multicolumn{2}{|c|}{$\begin{array}{l}\text { Unstandardized } \\
\text { Coefficients }\end{array}$} & \multirow{2}{*}{$\begin{array}{c}\text { Standardized } \\
\text { Coefficients } \\
\text { Beta }\end{array}$} & \multirow[t]{2}{*}{$\mathrm{T}$} & \multirow[t]{2}{*}{ Sig. } \\
\hline & & $\mathrm{B}$ & $\begin{array}{l}\text { Std. } \\
\text { Error }\end{array}$ & & & \\
\hline \multirow[t]{3}{*}{1} & (Constant) & 3,063 & 2,224 & & 1,377 & ,172 \\
\hline & $\begin{array}{l}\text { Daya } \\
\text { Tarik Iklan }\end{array}$ & ,327 & , 075 & ,356 & 4,367 & ,000 \\
\hline & $\begin{array}{l}\text { Label } \\
\text { Halal }\end{array}$ & ,592 & ,082 & ,589 & 7,225 & ,000 \\
\hline
\end{tabular}

Berdasarkan tabel diatas dapat diketahui persamaan regresi linier berganda sebagai berikut:

$$
Y=3,063+0,327 X_{1}+0,592 X_{2}
$$

Dari persamaan tersebut dapat diketahui :

a) Konstanta sebesar 3,063, artinya bahwa nilai konsisten variabel minat beli konsumen adalah sebesar 3,063.

b) Koefisien regresi $\mathrm{X}_{1}$ sebesar 0,327 menyatakan bahwa setiap penambahan $1 \%$ nilai daya tarik iklan, maka minat beli konsumen akan bertambah sebesar 3,063.

c) Koefisien regresi $X_{2}$ sebesar 0,592 menyatakan bahwa setiap penambahan $1 \%$ nilai label halal, maka minat beli konsumen akan bertambah sebesar 0,592 . 


\section{c. Analisis Korelasi}

1. Analisis Korelasi Sederhana

Tabel 4.11

Hasil uji Korelasi Sederhana Daya Tarik Iklan

Terhadap Minat Beli Konsumen

\begin{tabular}{|l|l|r|r|}
\hline \multicolumn{3}{|c|}{ Correlations } \\
\hline \multicolumn{2}{|c|}{} & $\begin{array}{r}\text { Daya } \\
\text { Tarik } \\
\text { Iklan }\end{array}$ & $\begin{array}{c}\text { Minat Beli } \\
\text { Konsume } \\
n\end{array}$ \\
\hline Daya Tarik Iklan & Pearson Correlation & 1 &, $816^{* *}$ \\
\cline { 2 - 4 } & Sig. (2-tailed) & 80 &, 000 \\
\cline { 2 - 4 } & $\mathrm{N}$ &, $816^{* *}$ & 80 \\
\hline Minat Beli Konsumen & Pearson Correlation &, 000 & 1 \\
\cline { 2 - 4 } & Sig. (2-tailed) & 80 & 80 \\
\cline { 2 - 4 } & $\mathrm{N}$ & & \\
\hline$* *$ Correlation is significant at the 0.01 level (2-tailed).
\end{tabular}

Berdasarkan tabel diatas, diperoleh nilai Pearson Correlation sebesar 0,816 karena hasil tersebut berada diantara $0,80-1,000$ maka dapat disimpulkan bahwa terdapat hubungan yang sangat kuat antara daya tarik iklan terhadap minat beli konsumen.

Tabel 4.12

Hasil Uji Korelasi Sederhana Label Halal Terhadap Minat Beli Konsumen

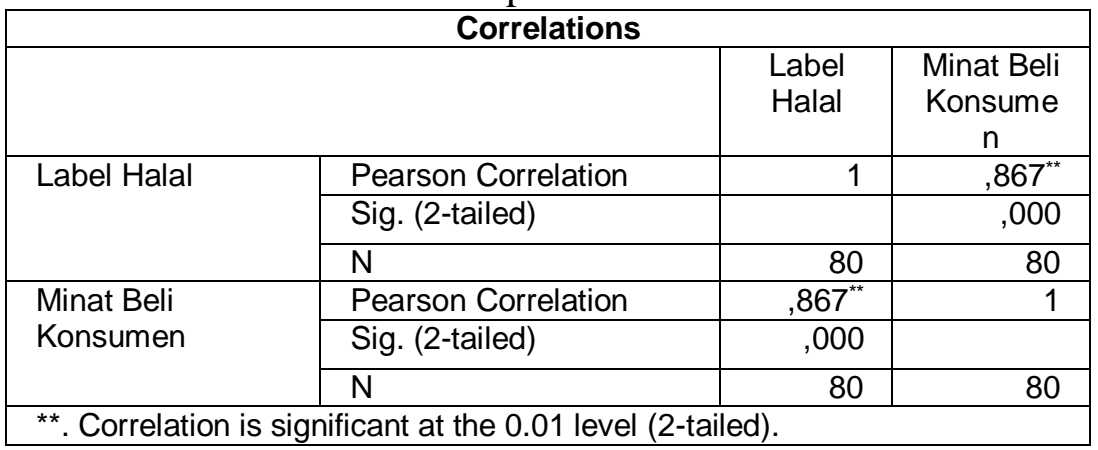

Berdasarkan tabel diatas, diperoleh nilai Pearson Correlation sebesar 0,867 karena hasil tersebut berada diantara 0,80 - 0,1000 maka dapat disimpulkan bahwa terdapat hubungan yang sangat kuat antara variabel label halal terhadap minat beli konsumen. 


\section{d. Analisis Korelasi Berganda}

Table 4.13

Hasil Uji Korelasi Berganda

\begin{tabular}{|c|c|c|c|c|}
\hline \multicolumn{5}{|c|}{ Model Summary } \\
\hline Model & $\mathrm{R}$ & R Square & $\begin{array}{c}\text { Adjusted R } \\
\text { Square }\end{array}$ & $\begin{array}{c}\text { Std. Error of } \\
\text { the Estimate }\end{array}$ \\
\hline 1 &, $895^{\mathrm{a}}$ &, 801 &, 795 & 2,256 \\
\hline \multicolumn{5}{|c|}{ a. Predictors: (Constant), Label Halal, Daya Tarik Iklan } \\
\hline
\end{tabular}

Berdasarkan tabel diatas, diperoleh nilai koefisien korelasi $(\mathrm{R})$ sebesar 0,895 karena hasil tersebut berada diantara $0,80-0,1000$ maka dapat disimpulkan bahwa terdapat hubungan yang kuat antara variabel daya tarik iklan dan label halal terhadap minat beli konsumen.

\section{e. Uji t}

Tabel 4.14

Uji Daya Tarik Iklan Terhadap

Minat Beli Konsumen

\begin{tabular}{|c|c|c|c|c|c|}
\hline \multicolumn{6}{|c|}{ Coefficients $^{a}$} \\
\hline \multirow[t]{2}{*}{ Model } & \multicolumn{2}{|c|}{$\begin{array}{l}\text { Unstandardized } \\
\text { Coefficients }\end{array}$} & $\begin{array}{l}\text { Standardized } \\
\text { Coefficients }\end{array}$ & \multirow[t]{2}{*}{$t$} & \multirow[t]{2}{*}{ Sig. } \\
\hline & $\mathrm{B}$ & $\begin{array}{l}\text { Std. } \\
\text { Error }\end{array}$ & Beta & & \\
\hline $\begin{array}{l}\text { (Consta } \\
\text { nt) }\end{array}$ & 9,773 & 2,600 & & $\begin{array}{r}3,75 \\
9\end{array}$ & ,000 \\
\hline $\begin{array}{l}\text { Daya } \\
\text { Tarik } \\
\text { Iklan }\end{array}$ & ,750 & ,060 & ,816 & $\begin{array}{r}12,4 \\
58\end{array}$ & ,000 \\
\hline
\end{tabular}

Dari tabel diatas diketahui bahwa t hitung sebesar 12,458 dengan taraf signifikansi 5\% Uji 2 sisi dan $\mathrm{df}=\mathrm{n}-2=80-2=78$, sehingga didapat $\mathrm{t}$ tabel sebesar 1,664 dengan demikian dapat disimpulkan bahwa $\mathrm{t}$ hitung 12,458 > t tabel 1,664 dan nilai sig 0,000 $<0,05$ artinya $\mathrm{Ha}_{1}$ diterima dan $\mathrm{Ho}_{1}$ ditolak sehingga terdapat pengaruh Daya Tarik Iklan (X1) terhadap Minat Beli Konsumen (Y). 
Tabel 4.15

Uji Label Halal Terhadap

Minat Beli Konsumen

\begin{tabular}{|c|c|c|c|c|c|}
\hline \multicolumn{6}{|c|}{ Coefficients $^{\mathrm{a}}$} \\
\hline \multirow[t]{2}{*}{ Model } & \multicolumn{2}{|c|}{$\begin{array}{l}\text { Unstandardized } \\
\text { Coefficients }\end{array}$} & $\begin{array}{l}\text { Standardized } \\
\text { Coefficients }\end{array}$ & \multirow[t]{2}{*}{$\mathrm{t}$} & \multirow[t]{2}{*}{ Sig. } \\
\hline & $\mathrm{B}$ & $\begin{array}{l}\text { Std. } \\
\text { Error }\end{array}$ & Beta & & \\
\hline 1 (Constant) & 5,360 & 2,398 & & $\begin{array}{r}2,23 \\
6\end{array}$ & ,029 \\
\hline $\begin{array}{l}\text { Label } \\
\text { Halal }\end{array}$ & 872 & 057 & ,867 & $\begin{array}{r}15,3 \\
50\end{array}$ & ,000 \\
\hline
\end{tabular}

Dari tabel diatas diketahui bahwa t hitung sebesar 15,350 dengan taraf signifikansi 5\%. Uji 2 sisi dan $\mathrm{df}=\mathrm{n}-2=80-2=78$, sehingga didapat $\mathrm{t}$ tabel sebesar 1,664 dengan demikian dapat disimpulkan bahwa t hitung 15,350 > t tabel 1,664 dan nilai sig $0,000<0,05$ artinya $\mathrm{Ha}_{1}$ diterima dan $\mathrm{Ho}_{1}$ ditolak sehingga terdapat pengaruh Label Halal (X2) terhadap Minat Beli Konsumen (Y).

\section{f. UJI F}

Tabel 4.16

Hasil Uji F

\begin{tabular}{|c|c|c|c|c|c|c|}
\hline \multicolumn{7}{|c|}{ ANOVA $^{a}$} \\
\hline \multicolumn{2}{|c|}{ Model } & Sum of & df & Mean Square & $\mathrm{F}$ & Sig. \\
\hline \multirow[t]{3}{*}{1} & $\begin{array}{l}\text { Regressi } \\
\text { on }\end{array}$ & 1574,409 & 2 & 787,205 & $\begin{array}{r}154,6 \\
38\end{array}$ & $\begin{array}{r}, 000 \\
b\end{array}$ \\
\hline & Residual & 391,978 & 77 & 5,091 & & \\
\hline & Total & 1966,388 & 79 & & & \\
\hline \multicolumn{7}{|c|}{ a. Dependent Variable: Minat Beli Konsumen } \\
\hline \multicolumn{7}{|c|}{ b. Predictors: (Constant), Label Halal, Daya Tarik Iklan } \\
\hline
\end{tabular}

Dari tabel diatas diketahui $\mathrm{F}$ hitung sebesar 154,638 dengan taraf signifikansi 5\% df $1=\mathrm{k}-1 \quad(3-1=2)$ dan df $2=\mathrm{n}-\mathrm{k}(80-3=77)$ diperoleh $\mathrm{F}$ tabel sebesar 3,12. Dengan demikian berdasarkan hasil tabel tersebut dapat disimpulkan bahwa f hitung 154,638 > f tabel 3,12 dan nilai sig 0,000<0,05 artinya Ha diterima dan Ho ditolak sehingga terdapat pengaruh daya tarik iklan (X1) dan label halal (X2) secara simultan terhadap minat beli konsumen (Y). 


\section{E. Kesimpulan \\ 1. Kesimpulan}

Berdasarkan hasil

penelitian, diperoleh kesimpulan bahwa daya tarik iklan dan label halal berpengaruh terhadap minat beli konsumen pada mahasiswi Universitas Muhammadiyah Tangerang (UMT), berikut ini adalah kesimpulan dari hasil penelitian:

a. Dari hasil penelitian diketahui bahwa terdapat pengaruh yang sangat kuat antara daya tarik iklan dengan minat beli konsumen mahasiswi Universitas Muhammadiyah Tangerang (UMT) dengan hasil olah data :

1) Nilai koefisien determinasi 0,816 .

2) Nilai pengujian $t$ memperoleh $t_{\text {hitung }}>t_{\text {tabel }}$ $(12,458>1,664)$. Ini berarti Ho ditolak dan $\mathrm{Ha}$ diterima.

3) Memiliki nilai signifikan sebesar 0,000. Nilai ini lebih kecil dari 0,05 (0,000 $<0,05)$. Sehingga dapat disimpulkan bahwa daya tarik iklan berpengaruh positif dan signifikan terhadap minat beli konsumen.

b. Dari hasil penelitian diketahui bahwa terdapat pengaruh yang sangat kuat antara label halal dengan minat beli konsumen pada mahasiswi
Universitas Muhammadiyah Tangerang (UMT) dengan hasil olah data :

1) Nilai koefisien determinasi 0,867 .

2) Nilai pengujian $t$ memperoleh $t_{\text {hitung }}>t_{\text {tabel }}$ $(15,350>1,664)$. Ini berarti Ho ditolak dan $\mathrm{Ha}$ diterima.

3) Memiliki nilai signifikan sebesar 0,000. Nilai ini lebih kecil dari 0,05 (0,000 $<0,05)$. Sehingga dapat disimpulkan bahwa label halal berpengaruh positif dan signifikan terhadap minat beli konsumen.

c. Dari hasil penelitian uji f diperoleh kesimpulan bahwa variabel daya tarik iklan mempunyai pengaruh yang signifikan terhadap minat beli konsumen. Hal ini ditunjukan pada hasil perhitungan SPSS 20 yang menjelaskan bahwa nilai $F_{\text {hitung }}>F_{\text {tabel }}(154,638>$ 3,12) maka, Ho ditolak Ha diterima. Hal ini menunjukan bahwa variabel daya tarik iklan dan label halal secara simultan berpengaruh positif dan signifikan terhadap variabel minat beli konsumen. Dengan demikian hipotesis menyatakan bahwa terdapat pengaruh yang positif atau signifikan daya tarik iklan dan label halal terhadap minat beli konsumen. 


\section{DAFTAR PUSTAKA}

Abdurrahman Konoras. 2017. Jaminan

Produk Halal di Indonesia

Perspektif

Hukum

Perlindungan Konsumen.

Rajawali Press: Depok.

Abdul Rauf dan Ismayudin Yuliyzar.

2016.

Manajemen

Pemasaran, CV Grafika Arta

Nawala: Jakarta.

Ali Hasan. 2014. Marketing dan

Kasus-Kasus Pilihan. CAPS:

Yogyakarta.

A.Shimp, Terence. 2014. Komunikasi

Pemasaran Terpadu dalam

Periklanan dan Promosi.

Salemba Empat: Jakarta.

Buchari Alma. 2014. Manajemen

Pemasaran dan Pemasaran

Jasa. Alfabeta: Bandung.

Buchari Alma. 2018. Manajemen

Pemasaran dan Pemasaran

Jasa. Alfabeta: Bandung.

Donni Juni Priansa. 2017. Komunikasi

Pemasaran Produk. Pustaka

Setia: Bandung.

Gunawan Adisaputro. 2014.

Manajemen Pemasaran. UPP

STIM YKPN: Yogyakarta.

Hasibuan, Malayu SP. 2018. Sumber

Daya ManusiaEdisi Revisi.

PT Bumi Aksara: Jakarta.

Hery. 2019. Manajemen Pemasaran.

PT Gramedia Widiasarana

Indonesia: Jakarta.

Herlambang, Susatyo. 2014. Basic

Marketing (Dasar-dasar

Marketing) Cara Mudah

Memahami Ilmu Pemasaran.

Gosyeng Publishing:

Yogyakarta.

Kotler dan Amstrong. 2014. Principle of Marketing. (Edisi Empat Belas). Erlangga: Jakarta.
Kotler dan Kevin Lane Keller. 2018. Manajemen Pemasaran. Erlangga: Jakarta.

Morissan. 2015. Teori Komunikasi Individu Hingga Massa. Kencana: Bandung.

Nadirsyah Hosen. 2015. Hukum Makanan tanpa Label Halal hingga Memilih Mazhab yang cocok. Mizania: Jakarta.

Philip Kotler dan Kevin Lane Keller. 2015. Manajemen Pemasaran (Jilid 1) (Edisi 13). Erlangga: Jakarta.

Sofyan Hasan. 2016. Sertifikasi Halal dalam Hukum Positif. Aswaja: Yogyakarta.

Sudaryono. 2014. Perilaku Konsumen Dalam Prespektif Pemasaran. Lantera Ilmu Cendekia: Jakarta.

Sudaryono. 2017. Manajemen Pemasaran dan Teori Implementasi. Andi: Yogyakarta.

Sugiyono. 2015. Metode Penelitian Kuantitatif, Kualitatif, dan $R \& D$. PT.Alfabeta: Bandung

Sugiyono. 2016. Metode Penelitian Kuantitatif, Kualitatif, dan $R \& D$. PT.Alfabeta: Bandung.

Sugiyono. 2017. Metode Penelitian Kuantitatif, Kualitatif, dan $R \& D$. Alfabeta: Bandung.

Sugiyono. 2018. Metode Penelitian Kuantitatif. PT.Alfabeta: Bandung.

Terry, George R dan Leslie W.Rue. $2014 . \quad$ Dasar-Dasar Manajemen. penerjemah G.A Ticoalu. PT Bumi Aksara: Jakarta 
Thamrin, HM.2015. Pengantar Bisnis, Media Pustaka: Yogyakarta.

Tjiptono, Fandy. 2014. Pemasaran Jasa. Andi: Yogyakarta

Yuswohady. 2014. Marketing to the Middle Class Muslim- Kenali Perubahannya, Paham Perilakunnya, Petakan Strateginya. Gramedia Pustaka Utama: Jakarta..

Zulham. 2018. Peran Negara dalam Perlindungan Konsumen Muslim terhadap Produk
Halal (Edisi Pertama). Kencana: Jakarta.

http://www.halalmui.org/mui14/Diaks es (19 Maret 2019, 20:17) http://www.halalmui.org/muil4/index. php/main/ceklogin_halal/produk_halal masuk/1Diakses (19 Maret 2019, 20:36)

https://www.paragon-innovation.com/ Diakses (15 Agustus 2019, 13:17)

https://www.paragon-

innovation.com/about-paragon Diakses (15 Agustus 2019, 14:03) 